\title{
Role of ACE and AGT gene polymorphisms in genetic susceptibility to diabetes mellitus type 2 in a Brazilian sample
}

\author{
L.M. Wollinger ${ }^{1}$, S.M. Dal Bosco ${ }^{1}$, C. Rempel ${ }^{2}$, S.E.M. Almeida ${ }^{3}$, D.B. Berlese ${ }^{3}$, \\ R.P. Castoldi' ${ }^{1}$, M.E. Arndt' ${ }^{4}$, V. Contini ${ }^{1}$ and J.P. Genro ${ }^{1,5}$ \\ ${ }^{1}$ Programa de Pós-Graduação em Biotecnologia, Centro Universitário UNIVATES, \\ Lajeado, RS, Brasil \\ ${ }^{2}$ Programa de Pós-Graduação em Ambiente e Desenvolvimento, \\ Centro Universitário UNIVATES, Lajeado, RS, Brasil \\ ${ }^{3}$ Programa de Pós-Graduação em Qualidade Ambiental, Universidade FEEVALE, \\ Novo Hamburgo, RS, Brasil \\ ${ }^{4}$ Serviço de Hemodinâmica, Hospital Bruno Born, Lajeado, RS, Brasil \\ ${ }^{5}$ Programa de Pós-Graduação em Biociências, \\ Universidade Federal de Ciências da Saúde de Porto Alegre, \\ Porto Alegre, RS, Brasil \\ Corresponding author: J.P. Genro \\ E-mail: juliag@ufcspa.edu.br
}

Genet. Mol. Res. 14 (4): 19110-19116 (2015)

Received August 12, 2015

Accepted October 7, 2015

Published December 29, 2015

DOI http://dx.doi.org/10.4238/2015.December.29.20

ABSTRACT. The aim of the current study was to investigate the association between the InDel polymorphism in the angiotensin I-converting enzyme gene $(A C E)$ and the rs699 polymorphism in the angiotensinogen gene $(A G T)$ and diabetes mellitus type 2 (DM2) in a sample population from Southern Brazil. A case-control study was conducted with 228 patients with DM2 and 183 controls without DM2. The ACE InDel polymorphism was genotyped by polymerase chain reaction (PCR) with specific primers, followed by electrophoresis on $1.5 \%$ agarose gel. The AGT rs699 polymorphism was genotyped using a real-time PCR assay. No significant 
association between the ACE InDel polymorphism and DM2 was detected $(\mathrm{P}=0.97)$. However, regarding the $A G T$ rs699 polymorphism, DM2 patients had a significantly higher frequency of the $A G$ genotype and lower frequency of the $G G$ genotype when compared to the controls $(P=0.03)$. Our results suggest that there is an association between the AGT rs699 polymorphism and DM2 in a Brazilian sample.

Key words: DM2; Angiotensinogen; Angiotensin I; AGT; ACE; RAS

\section{INTRODUCTION}

The renin-angiotensin system (RAS) acts as an endocrine system, regulating enzyme production and release and controlling signaling pathways through renins, angiotensins, angiotensin-converting enzymes, and angiotensinogen, which function to control blood pressure. Furthermore, the RAS is also related to homeostatic balance as well as circulatory and kidney functions (Abadir et al., 2012; Zhou et al., 2013a). Importantly, imbalances in RAS functions are related to insulin resistance and to susceptibility to diabetes mellitus type 2 (DM2).

DM2 represents a complex pathophysiology characterized by stages of altered fasting glucose, decreased glucose tolerance, insulin resistance, and pancreatic beta cell dysfunction. Chronic hyperglycemia is associated with the appearance of complications in several tissues including the eyes, kidneys, heart, and blood vessels. Individuals diagnosed with DM2 tend to be at higher risk of developing atherosclerosis or other cardiovascular diseases that significantly impair their lives (American Diabetes Association, 2014). Currently, there are approximately 340 million people with DM2 worldwide (4.1\% of the total population) (World Health Organization, 2013). The high prevalence and severe complications associated with this disease make DM2 a major public health problem. In Brazil, the regions with the highest number of affected individuals are Southern and Southeastern Brazil (Sartorelli and Franco, 2003).

The complex physiopathology of DM2 reflects an equally complex etiology. DM2 is considered a multifactorial disease, influenced by environmental and genetic factors. Familial studies have demonstrated that siblings of individuals with DM2 are 4 to 6 times more likely to develop the disease (Florez et al., 2003). Additionally, studies have estimated that the heritability of DM2 is around of 25\% (Poulsen et al., 1999). However, when individuals between the ages of 30 and 60 are considered, this measure may reach up to $70 \%$ (Almgren et al., 2011), which reinforces the role of genetic factors in this disease. Several genes have already been investigated in relation to DM2, which have been studied from the perspective of candidate gene approaches as well as by genome wide association studies (GWAS), and this has led to the identification of more than 70 loci associated with the disease (Sun et al., 2014).

Genes coding for proteins involved in the RAS system have also previously been investigated in regards to DM2 susceptibility. The InDel polymorphism of the ACE gene and the rs699 polymorphism of the AGT gene are among the most well-studied polymorphisms in DM2; however, there are contradictory results concerning certain populations and these risk alleles (Niu et al., 2010; Zhou et al., 2012; Ding et al., 2012; Al-Rubeaan et al., 2013). Given that there are inconsistencies in the literature, the role of these genetic variants in the susceptibility to DM2 is not yet clear, and therefore the aim of the current study was to assess the association between the ACE InDel and AGT rs699 gene polymorphisms and DM2 in a sample of Brazilian patients. 


\section{MATERIAL AND METHODS}

This is a case-control study comprised of 228 adults with DM2 and 183 without the disease from Southern Brazil. DM2 patients were recruited from Basic Health Units (BHU) in the regions of Vale do Taquari and Vale do Rio dos Sinos in the Rio Grande do Sul State. The control group was composed of individuals from the same BHU and from the hemodynamic service of the hospital Bruno Born in Lajeado, the main city in Vale do Taquari. Individuals of both genders were included in the study, and signed informed consent was obtained from all study participants in accordance with the Declaration of Helsinki.

DM2 was diagnosis as fasting glucose above $126 \mathrm{mg} / \mathrm{dL}$. Individuals with normal glucose levels (lower than $99 \mathrm{mg} / \mathrm{dL}$ ) and glycated hemoglobin levels (HbA1c) lower than 6.5\% were enrolled into the control group. Individuals with kidney diseases, or those with mental deficiencies who did not understand the consent form, were excluded.

For all individuals, the body mass index (BMI) was calculated using the following formula: current weight $(\mathrm{kg}) /$ height $(\mathrm{m})^{2}$ (World Health Organization, 1998). Weight and height were measured with the portable PLENNA digital scale (São Paulo, SP, Brazil) and SANNY stadiometer (São Paulo, SP, Brazil), respectively. Hypertension diagnosis was considered as the presence of systolic blood pressure higher than or equal to $120 \mathrm{mmHg}$ or diastolic blood pressure higher than or equal to $90 \mathrm{mmHg}$ according to the VI Brazilian Hypertension Guideline (Sociedade Brasileira de Cardiologia / Sociedade Brasileira de Hipertensão / Sociedade Brasileira de Nefrologia, 2010).

In order to obtain DNA samples, $5 \mathrm{~mL}$ peripheral blood were collected in tubes containing ethylenediaminetetraacetic acid (EDTA). DNA extraction was performed with a salting out procedure as described by Lahiri and Nurnberger (1991). The genotyping of the ACE InDel polymorphism was performed via polymerase chain reaction (PCR) with the following primer sequences: 5'-CTGGAGACCACTCCCATCCTTTCT-3' and 5'-ATGTGGCCATCACATTCGTCGTCAGAT-3'. The amplification was performed for 35 cycles $\left(94^{\circ} \mathrm{C}\right.$ for $1 \mathrm{~min} ; 55^{\circ} \mathrm{C}$ for $1 \mathrm{~min}$; and $72^{\circ} \mathrm{C}$ for $1 \mathrm{~min}$ ), and the PCR products were separated on $1.5 \%$ agarose gel at $90 \mathrm{~V}$ for $1 \mathrm{~h}$. Two DNA fragments were observed after electrophoresis: one 190-bp fragment indicating the Del allele, and one 490-bp fragment indicating the In allele. The genotyping of the AGT rs699 polymorphism was performed by real-time PCR with the TaqMan SNP genotyping assay according to manufacturer instructions (Applied Biosystems, Carlsbad, CA, USA).

Allelic frequencies were estimated by direct counting. The analyses of Hardy-Weinberg equilibrium (HWE) and of differences in allele and genotype frequencies between patients and controls were analyzed by chi-square tests. Potential confounders (i.e., clinical characteristics of the individuals) were considered using a statistical criterion (association with both the study factor and the outcome for $\mathrm{P} \leq 0.20$ ).

\section{RESULTS}

The DM2 group consisted of 228 patients and the control group consisted of 183 individuals without DM2 diagnosis. There were significant differences between patients and controls in the levels of fasting glucose and in the average BMI. The clinical characteristics of patients and controls are presented in Table 1.

Data regarding blood pressure were available for 157 individuals (56 patients and 101 controls), and hypertension diagnosis was present in $60 \%$ of the DM2 group and in $63 \%$ of the control group. Patients and controls did not differ in hypertension prevalence $(P=0.830)$. 
Table 1. Clinical characteristics of patients and controls.

\begin{tabular}{lcrr}
\hline & DM2 patients $(\mathrm{N}=228)$ & Controls $(\mathrm{N}=183)$ & P value \\
\hline Gender (males) & $82(36.0)$ & $77(42.1)$ & 0.245 \\
Age (years) & $60.54(10.8)$ & $56.93(10.9)$ & 0.135 \\
Glucose (mg/dL) & $152.48(58.8)$ & $83.49(12.4)$ & $<0.001$ \\
BMl $\left(\mathrm{kg} / \mathrm{m}^{2}\right)$ & $30.44(4.9)$ & $27.12(4.5)$ & $<0.001$ \\
\hline
\end{tabular}

Data are reported as $\mathrm{N}$ and (\%) or mean and (standard deviation). DM2 = diabetes mellitus type 2; BMI = body mass index.

Allele and genotype frequencies are presented in Table 2. The genotype frequencies of both polymorphisms did not deviate from the values expected according to the HWE. We found no significant differences in the allele and genotype frequencies for the ACE InDel polymorphism between patients and controls. In regards to the AGT rs699 polymorphism, a significant association with DM2 was observed $(P=0.030)$. Individuals with $D M 2$ had a higher frequency of the $A G$ genotype and a lower frequency of the GG genotype compared to those in the control group. BMI and glucose levels were not considered as covariates, since they were not associated with the $A G T$ genotypes for $\mathrm{P} \leq 0.20$.

Table 2. Genotype and allele frequencies of the ACE InDel and AGT rs699 polymorphisms in patients and controls.

\begin{tabular}{|c|c|c|c|}
\hline & DM2 patients $(\mathrm{N}=228)$ & Controls $(N=183)$ & $P$ value \\
\hline & $\mathrm{N}(\%)$ & $\mathrm{N}(\%)$ & \\
\hline \multicolumn{4}{|c|}{ InDel (ACE gene) } \\
\hline \multicolumn{4}{|c|}{ Genotypes } \\
\hline $\ln / \ln$ & $49(21.5)$ & $38(20.8)$ & \multirow[t]{3}{*}{0.970} \\
\hline In/Del & $114(50.0)$ & $91(49.7)$ & \\
\hline Del/Del & $65(28.5)$ & 54 (29.5) & \\
\hline \multicolumn{4}{|l|}{ Alleles } \\
\hline In & $212(46.5)$ & $167(45.6)$ & \multirow[t]{2}{*}{0.779} \\
\hline Del & $244(53.5)$ & $199(54.4)$ & \\
\hline \multicolumn{4}{|c|}{ rs699 ( $A G T$ gene) } \\
\hline \multicolumn{4}{|c|}{ Genotypes } \\
\hline GG & $43(18.9)$ & $50(27.3)$ & \multirow{3}{*}{$0.030^{\mathrm{a}}$} \\
\hline AG & $119(52.1)$ & 73 (39.9) & \\
\hline AA & $66(29.0)$ & $60(32.8)$ & \\
\hline \multicolumn{4}{|l|}{ Alleles } \\
\hline G & $205(44.9)$ & $173(47.2)$ & \multirow[t]{2}{*}{0.482} \\
\hline A & $251(55.1)$ & $193(52.8)$ & \\
\hline
\end{tabular}

\section{DISCUSSION}

There is strong evidence that genetic factors play important roles in DM2 etiology, and understanding these may help in diagnosis, prevention, and treatment, as well as to create more efficient public health strategies. However, it is necessary to emphasize that DM2 has a multifactorial etiology, and therefore it is expected that multiple genes influence the disease phenotype, each with a small effect. Although GWAS have identified some of the DM2 involved genes, those identified only account for 5 to $10 \%$ of the heritability of the disease (Sun et al., 2014). These results corroborate the idea that the candidate-gene approach may still be promising in elucidating the genetic factors involved in DM2, especially in different populations.

Our results did not show an effect of the ACE InDel polymorphism on DM2 predisposition

Genetics and Molecular Research 14 (4): 19110-19116 (2015)～ＯFUNPEC-RP www.funpecrp.com.br 
in our sample. This polymorphism is strongly associated with circulating levels of ACE, and individuals homozygous for the Del allele present with plasma levels of ACE twice as high as those in individuals who are homozygous for the In allele (Rigat et al., 1990; Norton et al., 2010). However, this variant is not located in a translated region of the gene, and hence it is possible that this polymorphism is in linkage disequilibrium with another functional variant that has not yet been identified (Norton et al., 2010).

Several meta-analyses have been performed in order to assess the role of the ACE InDel polymorphism in DM2 for different populations. For example, a study published in 2010 detected an association of the Del allele with DM2 in African and Caucasian populations (Niu et al., 2010). However, in another meta-analysis involving Chinese populations, this association was not observed (Zhou et al., 2012). In another recent meta-analysis, an association of the Del allele with DM2 was detected in an Arab population, although the same association was not observed in a Caucasian population (Al-Rubeaan et al., 2013). Considering these inconsistencies in the literature and our results reported herein, it is possible that this variant is important for susceptibility to DM2 in certain populations, and not important in others. For this reason, we hypothesize that genetic and allelic heterogeneity are important factors to be considered in the genetics of complex diseases. In this context, there may be other variants in this gene that influence the disease in our population, characterizing allelic heterogeneity. The other possibility is that this gene may not be important in certain subgroups within a population, in which other genes may influence the phenotype, characterizing genetic heterogeneity.

Regarding the AGT variant, our results indicate an association between the rs699 polymorphism and DM2. This polymorphism $(G \rightarrow A)$ represents a change in the amino acids from threonine to methionine at position 235 of the protein (M235T). This change in the protein seems to be reflected in AGT plasma concentrations where AA homozygous individuals present with an $11 \%$ higher concentration than that of GG homozygous individuals (Sethi et al., 2003). Our findings are in agreement with prior studies that have found an association between this polymorphism and DM2 (Young et al., 1998; Mehri et al., 2010). Additionally, meta-analyses have also reported associations between the A allele of the polymorphism and the risk of cardiovascular diseases (Wang and Pan, 2012, 2013; Liang et al., 2013a,b; Li et al., 2013; Chen et al., 2014), renal failure (Zhou et al., 2013b), pre-eclampsia (Lin et al., 2012), and breast cancer (Xi et al., 2011). However, a meta-analysis involving Caucasian and Asian individuals failed to detect an association between the rs699 polymorphism and diabetic nephropathy (Ding et al., 2012).

It is possible that the AGT rs699 polymorphism directly influences the predisposition to DM2. However, considering detected associations with other diseases, we can also suggest that this variant may be a marker for the severity of the disease, or even for a DM2 endophenotype. Unfortunately, we did not evaluate DM2 disease severity in this study. Another consideration is that the detected association with the AG genotype may suggest a different pattern of linkage disequilibrium of the rs699 polymorphism than that of other variants. For example, it has already been suggested that there are at least two functional variations of $A G T,-532 \mathrm{C}-\mathrm{T}$ and $-6 \mathrm{G}-\mathrm{A}$, which also influence protein levels (Inoue et al., 1997; Brand et al., 2002).

The results herein should be considered in the context of the following limitations. The limited number of individuals in the study samples can create false negative results. Additionally, it should be taken into account that DM2 is a complex phenotype, and it is expected that environmental factors also influence the disease. Therefore, the inclusion of environmental and other clinical variables not considered in this study could contribute to a better understanding of the role of the 
investigated genetic variants in DM2. Finally, it is important to highlight that despite all efforts to understand the influence of genetic variations in the development of a complex disease, they are not yet enough to determine the individual clinical risk of disease development, and thus more extensive analyses are necessary. Moreover, the genetic characteristics of each population need to be considered. Molecular studies may further help to clarify the physiopathology of DM2, and in the future, may help to identify at-risk individuals to prevent this disease before it appears as an important tool in public health.

In conclusion, our results demonstrated an association between the AGT rs699 polymorphism and DM2 in a Brazilian population. Nevertheless, more studies are required in order to confirm the role of this variant in the etiology of DM2.

\section{Conflicts of interest}

The authors declare no conflict of interest.

\section{ACKNOWLEDGMENTS}

The authors thank Fundação do Vale do Taquari de Educação e Desenvolvimento Social (FUVATES), Fundação de Amparo à Pesquisa do Estado do Rio Grande do Sul (FAPERGS), and Programa de Suporte à Pós-Graduação de Instituições de Ensino Particulares (CAPES/PROSUP) for financial support.

\section{REFERENCES}

Abadir PM, Walston JD and Carey RM (2012). Subcellular characteristics of functional intracellular renin-angiotesin systems. Peptides 38: 437-445.

Al-Rubeaan K, Siddiqui K, Saeb ATM, Nazir N, et al. (2013). ACE I/D and MTHFR C677T polymorphisms are significantly associated with type 2 diabetes in Arab ethnicity: A meta-analysis. Gene 520: 166-177.

Almgren P, Lehtovirta M, Isomaa B, Sarelin L, et al. (2011). Heritability and familiality of type 2 diabetes and related quantitative traits in the Botnia Study. Diabetologia 54: 2811-2819.

American Diabetes Association (2014). Diagnosis and classification of diabetes mellitus. Diabetes Care 37: S81-S90.

Brand E, Chatelain N, Paillard F, Tiret L, et al. (2002). Detection of putative functional angiotensinogen (AGT) gene variants controlling plasma AGT levels by combined segregation-linkage analysis. Eur. J. Hum. Genet. 10: 715-723.

Chen S, Zhang L, Wang HW, Wang XY, et al. (2014). The M235T polymorphism in the angiotensinogen gene and heart failure: a meta-analysis. J. Renin Angiotensin Aldosterone Syst. 15: 190-195.

Ding W, Wang F, Fang Q, Zhang M, et al. (2012). Association between two genetic polymorphisms of the renin-angiotensinaldosterone system and diabetic nephropathy: a meta-analysis. Mol. Biol. Rep. 39: 1293-1303.

Florez JC, Hirschhorn J and Altshuler D (2003). The inherited basis of diabetes mellitus: implications for the genetic analysis of complex traits. Annu. Rev. Genomics Hum. Genet. 4: 257-291.

Inoue I, Nakajima T, Williams CS, Quackenbush J, et al. (1997). A nucleotide substitution in the promoter of human angiotensinogen is associated with essential hypertension and affects basal transcription in vitro. J. Clin. Invest. 99: 1786-1797.

Lahiri DK and Nurnberger JI (1991). A rapid non-enzymatic method for the preparation of HMW DNA from blood for RFLP studies. Nucleic Acids Res. 19: 5444.

Liang B, Qin L, Wei H, Yan Y, et al. (2013a). AGT M235T polymorphisms and ischemic stroke risk: A meta-analysis. J. Neurol. Sci. 331: 118-125.

Liang X, Qiu J, Liu X, Li X, et al. (2013b). Polymorphism of angiotensinogen gene M235T in myocardial infarction and brain infarction: a meta-analysis. Gene 529: 73-79.

Li X, Li Q, Wang Y, Li Y, et al. (2013). AGT gene polymorphisms (M235T, T174M) are associated with coronary heart disease in a Chinese population. J. Renin Angiotensin Aldosterone Syst. 14: 354-359. 
Lin R, Lei Y, Yuan Z, Ju H, et al. (2012). Angiotensinogen gene M235T and T174M polymorphisms and susceptibility of preeclampsia: A meta-analysis. Ann. Hum. Genet. 76: 377-386.

Mehri S, Koubaa N, Hammami S, Mahjoub S, et al. (2010). Genotypic interactions of renin-angiotensin system genes with diabetes type 2 in a Tunisian population. Life Sci. 87: 49-54.

Niu W, Qi Y, Gao P and Zhu D (2010). Angiotensin converting enzyme D allele is associated with an increased risk of type 2 diabetes: evidence from a meta-analysis. Endocr. J. 57: 431-438.

Norton GR, Brooksbank R and Woodiwiss AJ (2010). Gene variants of the rennin-angiotensin system and hypertension: from a trough of disillusionment to a welcome phase of enlightenment? Clin. Sci. 118: 487-506.

Poulsen P, Ohm Kyvik K, Vaag A and Beck-Nielsen H (1999). Heritability of type II (non-insulin-dependent) diabetes mellitus and abnormal glucose tolerance - a population-based twin study. Diabetologia 42: 139-145.

Rigat B, Hubert C, Alhenc-Gelas F, Cambien F, et al. (1990). An insertion/deletion polymorphism of the angiotensin l-converting enzyme gene accounting for half of the variance of serum enzyme levels. J. Clin. Invest. 86: 1343-1346.

Sartorelli DS and Franco LJ (2003). Tendências do diabetes mellitus no Brasil: o papel da transição nutricional. Cad. Saude. Publica. 19: S29-S36.

Sethi AA, Nordestgaardt BG, Tybjaerg-Hansen A (2003). Angiotensinogen gene polymorphism, plasma angiotensinogen, and risk of hypertension and ischaemic heart disease: a meta-analysis. Arterioscler. Thromb. Vasc. Biol. 23: 1269-1275.

Sociedade Brasileira de Cardiologia / Sociedade Brasileira de Hipertensão / Sociedade Brasileira de Nefrologia (2010). VI Diretrizes Brasileiras de Hipertensão. Arq. Bras. Cardiol. 95: 1-51.

Sun X, Yu W and Hu C (2014). Genetics of type 2 diabetes: Insights into the pathogenesis and its clinical application. Biomed. Res. Int. 17: 1-16.

Wang YJ and Pan Y (2012). Angiotensinogen gene M235T polymorphism and risk of coronary artery disease: A meta-analysis. Mol. Med. Rep. 6: 884-888.

Wang YJ and Pan Y (2013). The M235T polymorphism in the angiotensinogen gene and myocardial infarction risk: A metaanalysis. J. Renin Angiotensin Aldosterone Syst. 0: 1-7.

WHO (World Health Organization) (1998). Physical status: the use and interpretation of anthropometry. Report of a WHO Expert Committee. WHO Technical Report Series 854. WHO, Geneva.

WHO (World Health Organization) (2013). Diabetes Programme. World Diabetes Day 2013. Available at [http://www.who.int/ diabetes/en/].

Xi B, Zeng T, Liu L, Liang Y, et al. (2011). Association between polymorphisms of the renin-angiotensin system genes and breast cancer risk: a meta-analysis. Breast Cancer Res. Treat. 130: 561-568.

Young RP, Chan JC, Critchley JA, Poon E, et al. (1998). Angiotensinogen T235 and ACE insertion/deletion polymorphisms associated with albuminuria in Chinese type 2 diabetic patients. Diabetes Care 21: 431-437.

Zhou D, Ruiter R, Zhang J, Zhou M, et al. (2012). Angiotensin-converting enzyme I/D polymorphism is not associated with type 2 diabetes in a Chinese population. J. Renin Angiotensin Aldosterone Syst. 13: 372-378.

Zhou JL, Ferrao FM, Zheng Y and Li XC (2013a). New frontiers in the intrarenal renin-angiotensin system: a critical review of classical and new paradigms. Front. Endocrinol. 4: 1-14.

Zhou TB, Yin SS and Qin YH (2013b). Association of angiotensinogen M235T gene polymorphism with end-stage renal disease risk: a meta-analysis. Mol. Biol. Rep. 40: 765-772. 